\title{
A link between low-frequency mesoscale eddy variability around Madagascar and the large-scale Indian Ocean variability
}

\author{
V. Palastanga, ${ }^{1}$ P. J. van Leeuwen, ${ }^{1}$ and W. P. M. de Ruijter ${ }^{1}$ \\ Received 1 June 2005; revised 1 May 2006; accepted 12 June 2006; published 26 September 2006.
}

[1] A connection is shown to exist between the mesoscale eddy activity around Madagascar and the large-scale interannual variability in the Indian Ocean. We use the combined TOPEX/Poseidon-ERS sea surface height (SSH) data for the period 19932003. The SSH-fields in the Mozambique Channel and east of Madagascar exhibit a significant interannual oscillation. This is related to the arrival of large-scale anomalies that propagate westward along $10^{\circ}-15^{\circ} \mathrm{S}$ in response to the Indian Ocean dipole (IOD) events. Positive (negative) SSH anomalies associated to a positive (negative) IOD phase induce a shift in the intensity and position of the tropical and subtropical gyres. A weakening (strengthening) results in the intensity of the South Equatorial Current and its branches along east Madagascar. In addition, the flow through the narrows of the Mozambique Channel around $17^{\circ} \mathrm{S}$ increases (decreases) during periods of a stronger and northward (southward) extension of the subtropical (tropical) gyre. Interaction between the currents in the narrows and southward propagating eddies from the northern Channel leads to interannual variability in the eddy kinetic energy of the central Channel in phase with the one in the SSH-field.

Citation: Palastanga, V., P. J. van Leeuwen, and W. P. M. de Ruijter (2006), A link between low-frequency mesoscale eddy variability around Madagascar and the large-scale Indian Ocean variability, J. Geophys. Res., 111, C09029, doi:10.1029/2005JC003081.

\section{Introduction}

[2] The mesoscale activity around Madagascar is related to the large-scale circulation in the Indian Ocean (IO) (Figure 1). The South Equatorial Current (SEC) flows westward between $10^{\circ}-20^{\circ} \mathrm{S}$ and on reaching the Madagascar coast at around $17^{\circ} \mathrm{S}$, splits into two branches. The northward branch forms at the northern tip of the island the North Madagascar Current (NMC), while the southern one feeds around $17^{\circ} \mathrm{S}$ into the East Madagascar Current (EMC) [Swallow et al., 1988]. At the southern tip of the island the EMC seems to experience a retroflection, in which eddies are shed from the current [Lutjeharms, 1988]. Westward continuation toward south Africa is another possible regime for the EMC after separation from the coast [Quartly and Srokosz, 2004]. The flow of the SEC north of Madagascar bifurcates again at the African coast where it forms to the north the East African Coastal Current (EACC) and to the south the Mozambique Current. Based on hydrographic observations Donguy and Piton [1991] described the existence of an anticyclonic circulation in the northern section of the Channel. Recent hydrographic measurements [de Ruijter et al., 2002] showed that there was no continuous Mozambique Current along the western boundary; instead southward

\footnotetext{
${ }^{1}$ Institute for Marine and Atmospheric Research, Utrecht University, Utrecht, Netherlands.

Copyright 2006 by the American Geophysical Union. 0148-0227/06/2005JC003081\$09.00
}

migrating anticyclonic eddies appeared to dominate the flow. Such eddies have also been suggested by tracking satellite sea level anomalies [Gründlingh, 1995; Schouten et al., 2002a], and were simulated in a numerical model [Biastoch and Krauss, 1999]. However, the observed eddies reached to the bottom while the modeled ones were limited to the upper layers. Suggested mechanisms for the eddy formation are barotropic instability of the SEC north of the Mozambique Channel (MZC) [Quadfasel and Swallow, 1986; Biastoch and Krauss, 1999] and shedding related to the geometry of the narrow section of the MZC when during strong current events the northern anticyclonic loop is pushed through the constriction [Ridderinkhof and de Ruijter, 2003].

[3] South of Madagascar cyclonic and anticyclonic eddies have been observed from altimetry propagating (south) westward toward the Agulhas Current (AC) [Gründlingh, 1995; Schouten et al., 2002a; Quartly and Srokosz, 2004]. Additionally, large pairs of counterrotating eddies or dipoles were discovered in this region and measured hydrographically [de Ruijter et al., 2004]. They also migrate into the Agulhas Retroflection system. From August-1996 to May-1997 and from May-1999 to June-2000 frequent and regular dipole formation appeared, separated by a long period in which hardly any dipoles or eddies were formed. de Ruijter et al. [2004] suggested that periods of regular dipole formation are related to a strengthening of the EMC due to large scale SSH anomalies from $\mathrm{La}$ Niña and/or Indian Ocean Dipole (IOD) negative events. Remarkably, the interaction between the train of dipoles in late 2000 and the AC caused an anomalous eastward shift of 


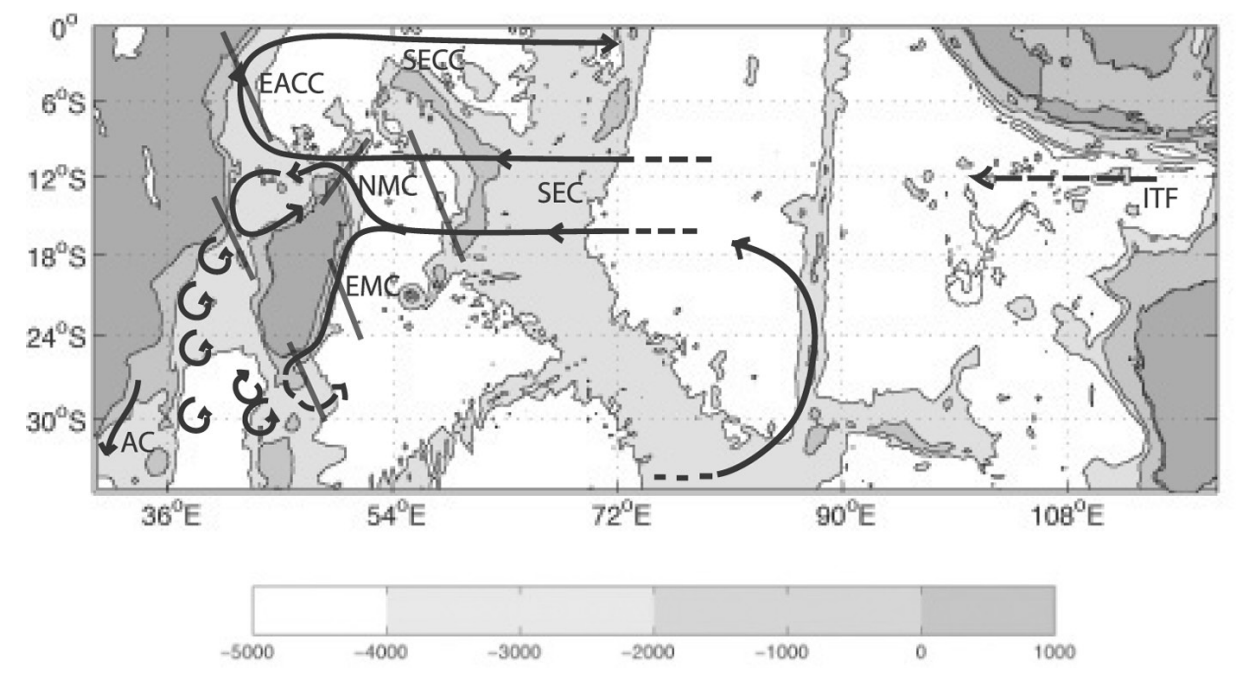

Figure 1. Schematic general circulation of the south Indian Ocean (SIO). North of $12^{\circ} \mathrm{S}$ the South Equatorial Current (SEC), East African Coastal Current (EACC) and SEC Countercurrent (only during the summer monsoon season, DJF) form the tropical gyre in the SIO. South of $12^{\circ} \mathrm{S}$ the SEC forms the northern boundary of the SIO subtropical gyre, and it splits at the coast of Madagascar into the North Madagascar Current (NMC) and East Madagascar Current (EMC). Eddies dominate the flow in the western Mozambique Channel and at around $27^{\circ} \mathrm{S}$ the Agulhas Current (AC) is formed along the African coast. The Indonesian Throughflow (ITF) enters the SIO basin between $10^{\circ}-15^{\circ} \mathrm{S}$. Sections along six satellite tracks used to derive geostrophic velocity anomalies are shown with gray thick lines.

the Agulhas retroflection that lasted almost half a year. No Agulhas Rings were formed during that period.

[4] Eddies in the MZC are dominated by a frequency of 4-5 times/year [Schouten et al., 2003]. Analysis of in situ and satellite observations revealed interannual variability in this frequency during 1996-2000; for instance, hardly any eddies were detected in the first half of 1996 and 1998. Schouten et al. [2002b] proposed that the rate of eddy formation in the MZC is modulated by varying equatorial winds through an oceanic teleconnection across the IO: equatorial Kelvin waves arrive at the Sumatra coast at the same 4 times/year frequency, they continue southward as coastal Kelvin waves, and subsequently trigger Rossby waves at $\sim 12^{\circ} \mathrm{S}$. Anomalous equatorial easterlies during the IOD and ENSO interrupted the chain of events in 1994 and 1997, leading to less eddies in the MZC after a lag related to the time it takes the Rossby waves to cross the IO along $12^{\circ} \mathrm{S}$ to Madagascar. Although the studies above have shown that the tropical climate modes in the IO induce interannual variability in the mesoscale eddy activity around Madagascar, a better understanding of such processes is needed.

[5] The main mode of interannual variability in the Tropical IO (TIO) is the IOD [Webster et al., 1999; Saji et al., 1999]. The IOD is characterized at the surface by a cooling front off Sumatra and warming in the central and western IO. An IOD index based on the difference of sea surface temperature (SST) anomalies between the western TIO and the southeastern TIO [Saji et al., 1999] during the last decade indicates positive (negative) events in 1991 (1992), 1994 (1996) and 1997 (1998). The event 1991/ 1992 was of lesser importance and will not be considered later on in this study; the other events are among the strongest IOD's of the last century [Rao et al., 2002]. Subtropical IOD signals are related to westward propagating Rossby waves [Rao et al., 2002; Feng and Meyers, 2003]; in particular, a subtropical downwelling Rossby wave is forced in the eastern-central IO by the wind curl anomalies during the positive phase. It further intensifies 'on the way' due to a positive convolution with the wind curl [Feng and Meyers, 2003]. It continues at the western boundary as a northbound Kelvin wave. Subsequently, the eastward propagation of a warm anomaly along the Equator brings a positive SST anomaly in the eastern IO in the following year of the IOD. This sequence of propagating waves imprints a 2 years timescale on the tropical IO variability.

[6] The forcing of the IOD is related to a positive wind curl anomaly in the eastern IO between $0^{\circ}-10^{\circ} \mathrm{S}$ [Saji et al., 1999]. Reason et al. [2000] described a similar wind curl pattern due to ENSO, but with anomalies extending further east into the Indonesian passages. Furthermore, anomalous winds around Indonesia due to both the IOD and ENSO alter the normal Indo-Pacific sea level gradient, which is the driving force of the Indonesian Throughflow (ITF): during El Niño (La Niña) events, a lower (higher) ITF transport is expected, and vice versa for the IOD phases [Meyers, 1996]. Murtugudde et al. [1998] verified this with a simple model, and found a large increase in the ITF during the 1994 IOD event. Wijffels and Meyers [2004] showed that ENSO signals enter the IO via the Indonesian Passages through the propagation of coastal Kelvin waves and subsequent Rossby waves from western Australia, though the latter are attenuated in the central IO by the effect of local wind-forcing. In the band $5^{\circ}-15^{\circ} \mathrm{S}$ Ekman pumping also strongly modifies interannual waves propagating westward from the eastern boundary [Masumoto and Meyers, 1998]. Rossby waves along $10^{\circ} \mathrm{S}$ seem to ultimately modulate the SST variability 
(a)

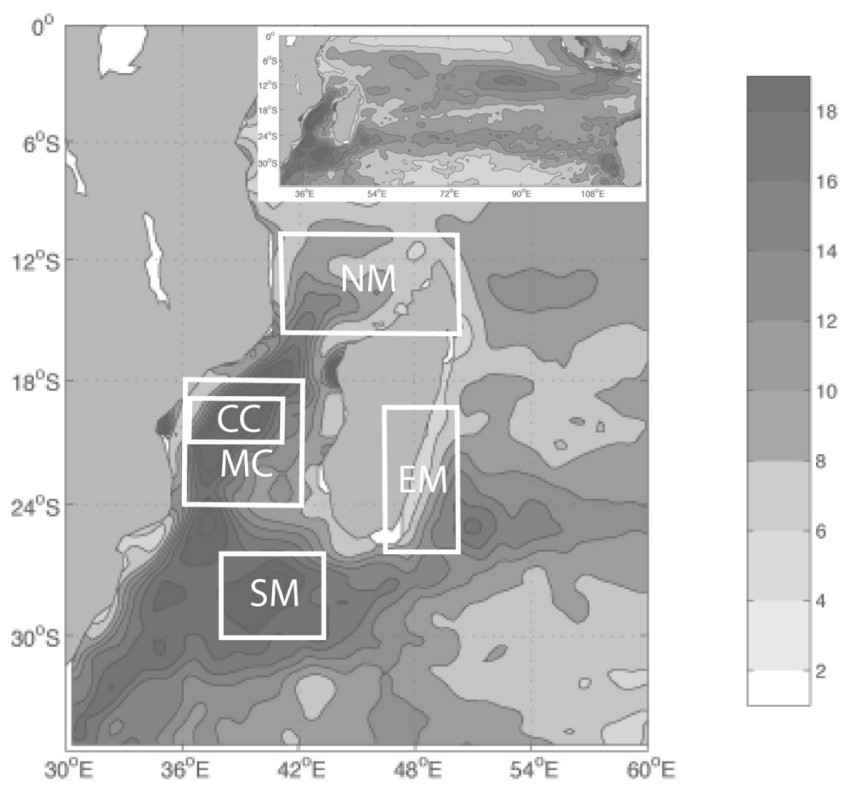

(b)

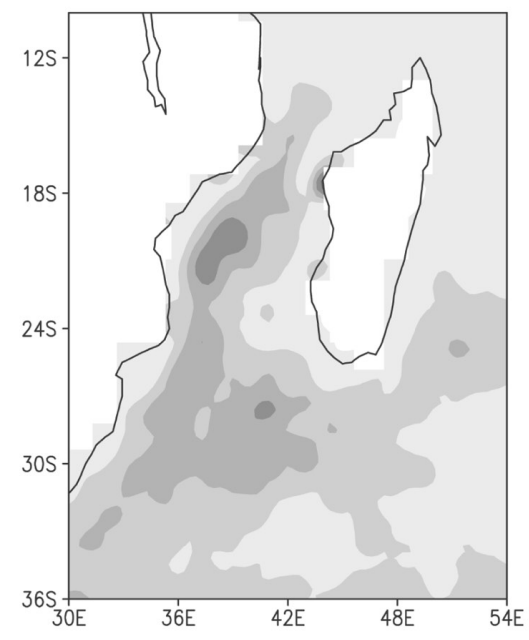

(c)

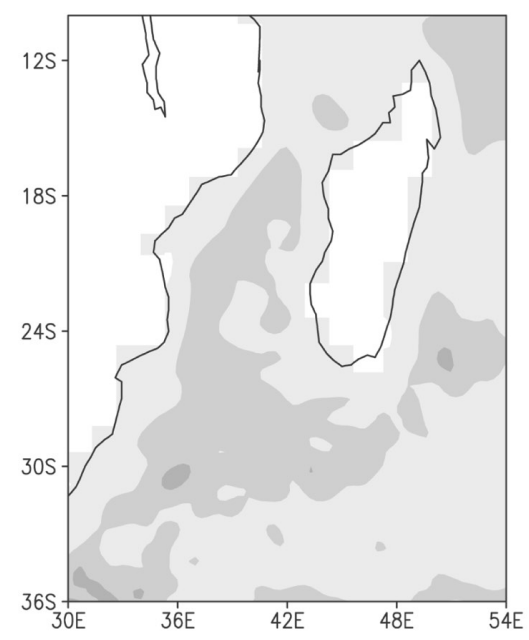

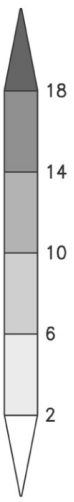

Figure 2. (a) Standard deviation of SSH anomalies from the combined T/P-ERS data set for the period 1993-2003. Five boxes in the graph display regions selected for a time series analysis, namely North Madagascar (NM), Mozambique Channel (MC), Central MC (CC), East Madagascar (EM), and Southwest Madagascar (SM). On the right upper corner, the variability over the South Indian Ocean is shown. (b) Standard deviation of the high passed SSH anomalies. A Lanczos filter with a cut off frequency of 0.125 month $^{-1}$ was applied. (c) Same as Figure 2b, but for the low-passed SSH anomalies. Units in cm.

in the western IO upwelling dome through thermoclinesurface feedbacks [Xie et al., 2002].

[7] The goal of the present study is to investigate whether (and how) large-scale sea surface height (SSH) anomalies generated in the TIO during the IOD impact the dynamics and variability in the region around Madagascar (i.e. between $12^{\circ}-25^{\circ} \mathrm{S}$ ) and, eventually, introduce the observed year-toyear variation in the local mesoscale eddy activity. After presenting the data in section 2 , section 3 deals with the description and analysis of the interannual variability in $\mathrm{SSH}$ and eddy kinetic energy (EKE) around Madagascar, based on the longest available period of satellite altimetry observations (i.e. over 10 years). In section 4 we analyze the propagation of large-scale SSH anomalies in the subtropical IO through a lag correlation analysis with an IOD index, and examine the modifying role of the subtropical wind curl variations along such propagation paths. Large-scale SSH anomalies near Madagascar will alter the local current regimes and their stability characteristics. Therefore, velocity variations in the boundary currents at the African and Madagascar coasts as well as in the branches of the SEC are analyzed and 
(a)

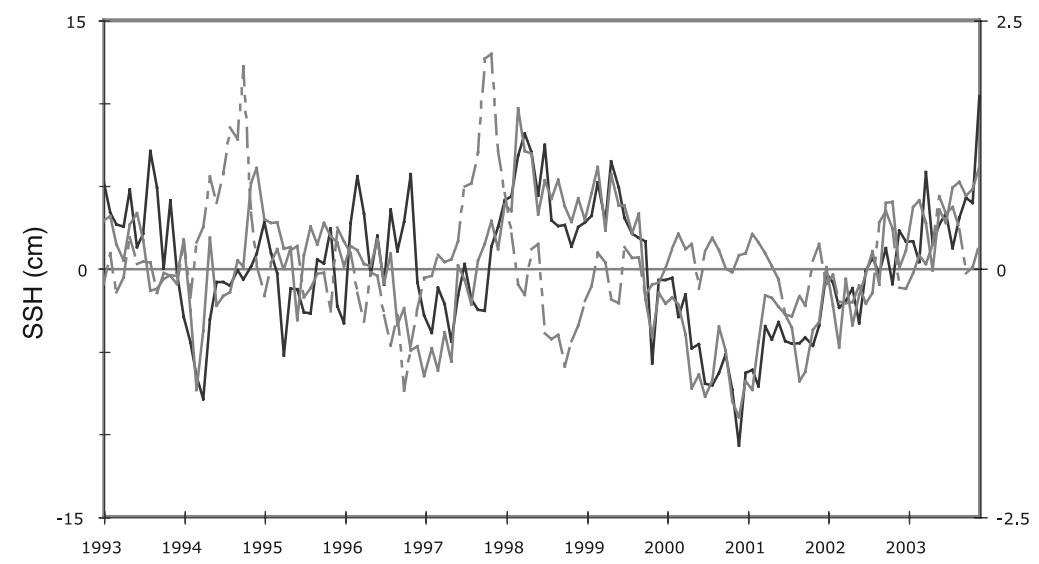

(b)

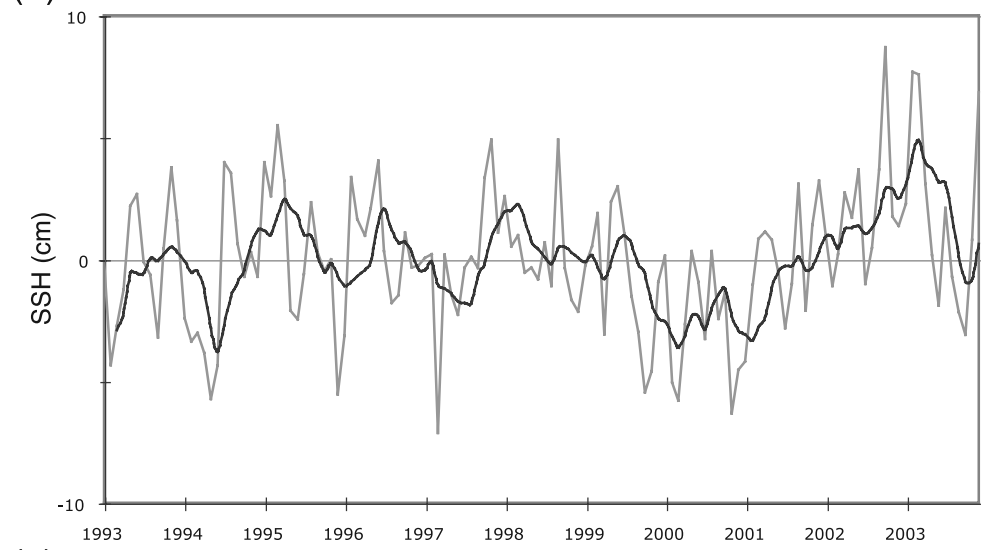

(c)

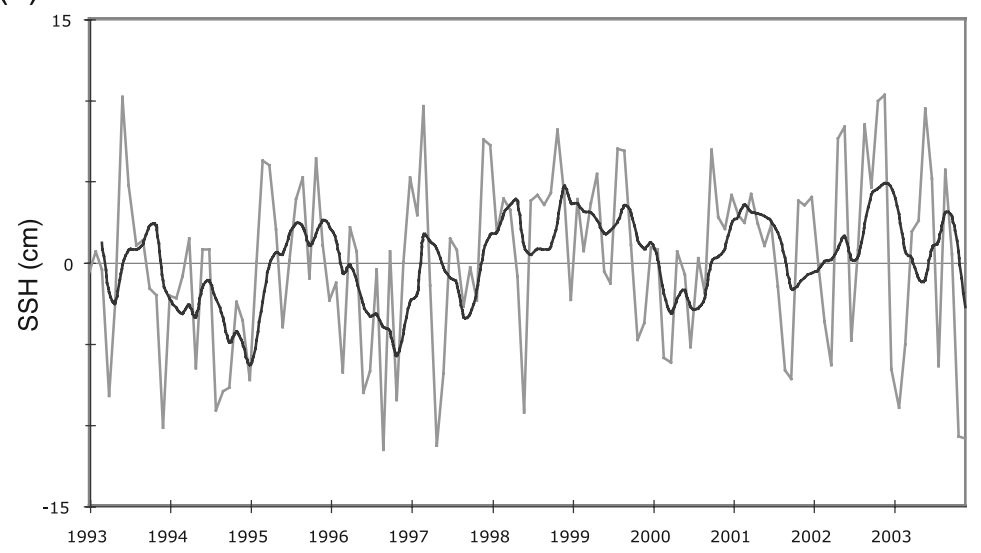

Figure 3. Time series of averaged SSH anomalies in the regions (a) North Madagascar (gray line) and Mozambique Channel (black line), (b) East Madagascar (gray line), (c) Southwest Madagascar (gray line). In Figures $3 b$ and $3 c$ a five months running mean of each series is added (black line). In Figure 3a the dash-dot line denotes the IOD index of Saji et al. [1999], with units in ${ }^{\circ} \mathrm{C}$.

connections between the current anomalies and eddy variability are discussed (section 5).

\section{Data}

[8] In this study we use SSH measurements from the TOPEX/Poseidon (T/P) and ERS satellite missions combined and processed on a $1 / 3^{\circ} \times 1 / 3^{\circ}$ grid by the CLS Space Oceanography Division, France. The selected data covers the period October 1992 to January 2004, with a time spacing of one week. Due to problems in the orbit of ERS from January 1994 to March 1995 only T/P data is included. This reduces the spatial resolution of the final product in that time period, as the number of tracks performed by $\mathrm{T} / \mathrm{P}$ per cycle is less than those of ERS. Also mapping errors in percentage of the signal variance are obtained for each weekly SSH. The domain of the study covers the IO region between $50^{\circ} \mathrm{S}$ to $20^{\circ} \mathrm{N}$ and $30^{\circ} \mathrm{E}$ to $120^{\circ} \mathrm{E}$. SSH anomalies (SSH from now on) were computed by removing the mean per calendar month from each monthly observation. For the 
analysis in section 4, SSH were further low-pass filtered using a Lanczos filter with a cut off frequency of 0.125 month $^{-1}$ [Duchon, 1979]. As the filter response function varies from 1 to 0 at frequencies from 0.094 month $^{-1}$ to 0.155 month $^{-1}$ by low-pass filtering, it is expected that energy at periods higher than 11 months remains unaltered.

[9] Additional to the combined SSH data product, $\mathrm{SSH}$ data along the tracks of T/P and ERS are analyzed. These are used to study the variability of western boundary currents that intercept the satellite tracks (section 5). Along each track the distance between SSH observations is about $6 \mathrm{~km}$, which makes it possible to resolve not only currents near the coast but also velocity anomalies, e.g. due to mesoscale eddies.

[10] Finally, monthly means of SST and surface wind vectors are obtained from the NCEP Reanalysis data set [Kalnay et al., 1996]. As for the SSH data, monthly anomalies were computed over 1992-2003.

\section{SSH and EKE Variability Around Madagascar}

[11] Two routes of high SSH variability from the region around Madagascar converge into the Agulhas Current path south of $25^{\circ} \mathrm{S}$ : one originates around $15^{\circ} \mathrm{S}$ in the $\mathrm{MZC}$ and continues south along its western side; the second one comes from the southeastern side of Madagascar and extends westward south of the island (Figure 2a). Most of the variability along these paths is related to the mesoscale eddies detected in the area [Gründlingh, 1995; Schouten et al., 2002a, 2003; de Ruijter et al., 2004]. This can be seen in the variability of the high passed SSH (Figure 2b), which shows that most of the variance is contained in the mesoscale field, whereas the low-frequency SSH (Figure 2c) has a similar distribution of variability but with lower amplitude. The two energetic areas around Madagascar are in turn influenced by the $\mathrm{SSH}$ variability along two zonal bands extending east of Madagascar across the $\mathrm{IO}$, around $12^{\circ} \mathrm{S}$ and $24^{\circ} \mathrm{S}$ (Figure 2a). These bands show significant Rossby wave activity at frequencies of around 4 times/year [Schouten et al., 2002a, $2002 \mathrm{~b}$ ]. While the variability along the $24^{\circ} \mathrm{S}$ band from off Australia up to $90^{\circ} \mathrm{E}$ also represents signals of westward propagating eddies from the Leewin Current [Fang and Morrow, 2003], its origin in the center of the subtropical gyre is related to baroclinic instability [Palastanga et al., 2006].

[12] To investigate the SSH year-to-year variations, time series over four selected regions around Madagascar are analyzed (see Figure 2a). The North region (NM) lies in an area where eddies are formed due to instabilities of the NMCjet [Quadfasel and Swallow, 1986] and where SSH anomalies arrive from the IO at interannual and shorter timescales [Perigaud and Delecluse, 1993; Schouten et al., 2002b]. In the MZC between $18^{\circ}-24^{\circ} \mathrm{S}$ (MC) the high-frequency SSH variability is related to eddies traveling regularly southward [Schouten et al., 2003]. The other two regions comprise an area east of Madagascar (EM) that includes the EMC region, and an area southwest of the island (SM), where the EMC has separated from the coast to continue its path westward or to retroflect eastward [Quartly and Srokosz, 2004]. Most of the eddies detached from the EMC at this point, as well as eddies coming from the $24^{\circ} \mathrm{S}$ band in the $\mathrm{IO}$, are expected to drift through the SM region before joining the AC regime.

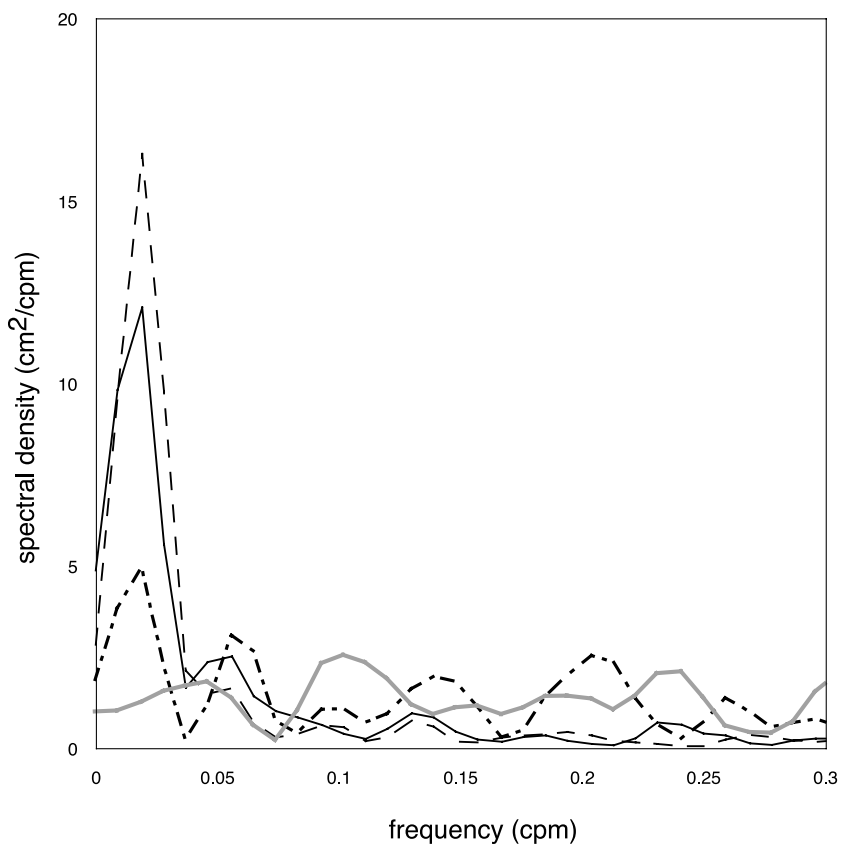

Figure 4. Spectral density $(\mathrm{cm})^{2} / \mathrm{cpm}(\mathrm{cpm}=$ cycles per month) versus frequency (per month) for the SSH time series in the regions North Madagascar (dashed line); Mozambique Channel (solid black line); East Madagascar (dashed-dotted line); Southwest Madagascar (solid gray line). Spectral peaks were tested with a red noise spectra and its confidence bands at the $90 \%$ significant level as discussed in the text.

\subsection{SSH Interannual Variations}

[13] The SSH in the NM and MC regions exhibit a similar interannual fluctuation that can be compared to the IOD evolution (Figure 3a). After the first positive (negative) IOD event, positive (negative) SSH appears in the two areas. However, after the second IOD event a two years period of positive $\mathrm{SSH}$ is followed by two years of negative $\mathrm{SSH}$. The $\mathrm{SSH}$ in the EM and SM regions is dominated by fluctuations at shorter timescales (Figures $3 b$ and $3 c$ ). The EM region also shows an interannual oscillation similar to that in NM and MC, with positive SSH in 1995 and from late 1997 to half 1999, the latter followed by negative SSH until 2001. The SSH in the SM region lag those in EM by a few months, but it exhibits relatively higher frequency oscillations. This may be related to local dynamical processes of the separating EMC. Moreover, the SM region lies in an area that could be directly affected by variability of the large-scale subtropical IO circulation, including the anticyclonic recirculation gyre in the southwest corner of the basin [Stramma and Lutjeharms, 1997].

[14] Effects of the ENSO-cycle on the SSH variability around Madagascar are also possible. Nicholson [1997] found significant coherence between the SST in both the MZC and an area south of Madagascar and the Southern Oscillation index (SOI) at periods of 4-6 years and in the quasibiennial range. The spectrum of the SOI is dominated by interannual variability at periods of 3.5 years and 5 years, whereas the IOD index shows variability at around 3 years period (not shown). A spectral analysis of the SSH time series in the NM, MC and EM regions reveals a peak at around 4.5 years period ( 0.019 cycles per month) (Figure 4$)$. The 
(a)

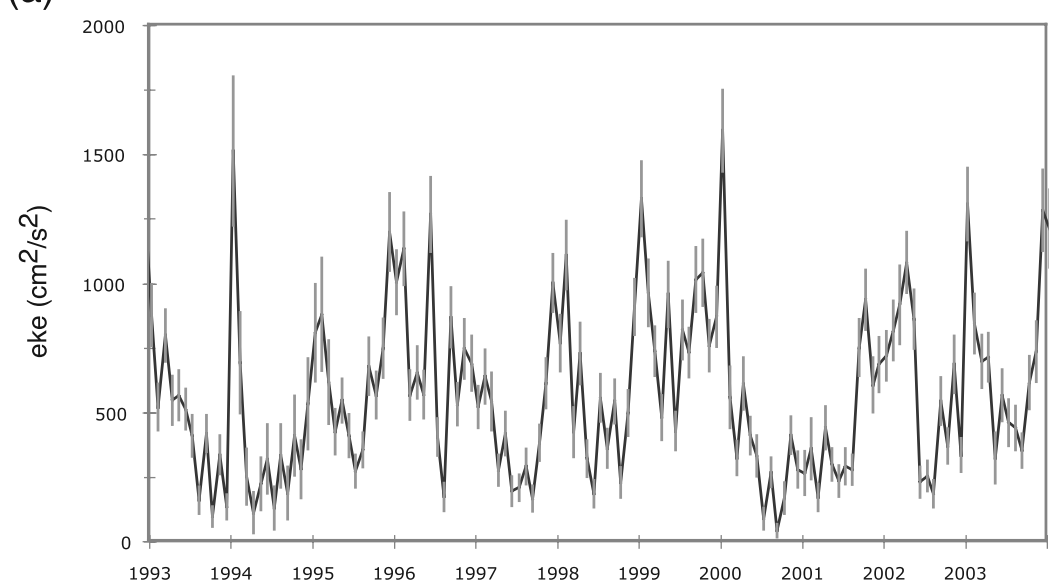

(b)

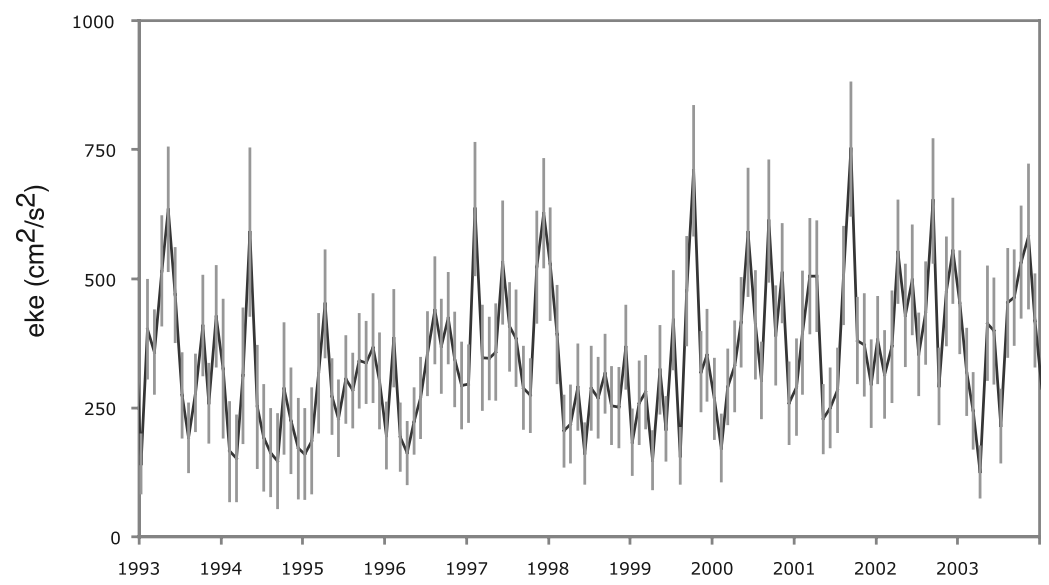

Figure 5. EKE time series in (a) the Central Mozambique Channel and (b) Southwest Madagascar. Error bars for each monthly EKE estimation are shown with gray segments. Errors are available as percentage of the signal variance for each weekly SSH field. Units in $(\mathrm{cm} / \mathrm{s})^{2}$.

interannual peaks lie close to the $95 \%$ confidence level from a red noise background estimation, and are significant at the $90 \%$ confidence level. They could reflect the large oscillation seen the last decade from half 1997 to half 2001 (Figure 3a); however, it is difficult to extract a conclusion on interannual variability from a 10 years record. The SSH in the SM region shows variability at subannual timescales $(0.1$ cycles per month), and also, though non-significant, at around 2 years period ( $\sim 0.046$ cycles per month) (Figure 4$)$.

\subsection{EKE Interannual Variations}

[15] To measure changes in the mesoscale activity around Madagascar, EKE time series are computed. Geostrophic velocity anomalies are estimated from the zonal and meridional SSH gradients multiplied by g/f; subsequently EKE is obtained as:

$$
E K E=\frac{1}{2}\left(u^{\prime 2}+v^{\prime 2}\right)
$$

This EKE estimation can only represent energy contained in anomalous surface currents under the geostrophic assumption. Schouten et al. [2003] combined T/P derived geostrophic velocity anomalies with in situ LADCP data to estimate total velocities in the MZC, and found a good correlation between the direction of the estimated total geostrophic flow and independent mooring observations. If we assume that the mean currents in MC are rather weak, and the same for the SM region, then geostrophic velocity anomalies may constitute a good indication of the variability due to eddies in these regions. A limitation in the analysis of EKE exists due to the lack of ERS satellite data from January 1994 until March 1995. The degraded spatial resolution of the original analysis over this period renders the EKE estimations not adequate for a study of eddy mesoscale features. Therefore, EKE variations are described from 1996 onwards. Because the frequency of eddy variability in the MZC reduces from 7 times/year in the northern toward 4 times/year in the central Channel [Schouten et al., 2003], and also because SSH anomalies show a strong amplitude increase toward the center, we chose a smaller region inside the $\mathrm{MC}$ region, the $\mathrm{CC}$ region (see Figure 2a), which better captures the signal of the southward propagating eddies (i.e. 4-5 time/year).

[16] The EKE in CC shows periods of high EKE (i.e. highly energetic eddies) in 1995-1996, 1998 and 1999 and of low EKE in 1997 and 2000-2001, with an EKE amplitude of $600-800 \mathrm{~cm}^{2} / \mathrm{s}^{2}$ (Figure 5a). Interestingly, this interannual variation is not present in the EKE in 
northern regions of the MZC. Although most of the EKE peaks associated with a positive $\mathrm{SSH}$ in CC could be traced to the Channel narrows $\left(17^{\circ} \mathrm{S}\right)$ about $1-2$ months earlier (not shown), their amplitude changes toward the $\mathrm{CC}$ region, resulting in the observed low-frequency variability. Periods of high (low) EKE in CC coincide with periods dominated by positive (negative) SSH in MC (Figure 3a). The correlation between the SSH and EKE time series is significant $(0.49)$ if the EKE is also averaged over the MC region.

[17] In the SM region periods of high EKE are observed from Aug 1996 through 1997 and from Oct 1999 until 2002 (Figure 5b), which can be associated to the first and second period of regular dipole formation [de Ruijter et al., 2004]. An EKE minimum spans the second half of 1998 to half1999. Due to the availability of data by that time, de Ruijter et al. [2004] could only track dipoles and analyze their variability from 1996 to 2000 . Here we have extended the analysis to 2003 and found that after "the train of 2000", two more dipoles were formed, namely in Jan 01 and Apr 01. Thereafter, no dipoles were observed until 2003. The EKE peaks in 2002 correspond to anticyclonic SSH anomalies. Vortex-pairs were observed again in Apr 03, Jul 03 and Dec 03, though in the last two cases of small size and amplitude, giving relatively lower EKE peaks (Figure 5b).

[18] A spectral analysis of the EKE in CC shows dominant variability at the annual period, and a second peak at around 3 years period (significant at the 90\% confidence level), whereas the EKE in the SM region shows variability around 5 years period, though not significant (not shown). Both regions also show a significant correlation with the IOD index of 0.47 in CC at a lag of 20 months and -0.29 in SM at a lag of 15 months, with the EKE lagging the IOD, suggesting a link between the EKE interannual variability in these regions and the IOD cycle. In the following, an explanation for lags and mechanisms of such a response to the IOD is examined.

\section{Large-Scale Response of SSH to the IOD Cycle}

[19] To relate the SSH and EKE variations observed near Madagascar with the large-scale variability over the IO, we investigate the evolution of the basin scale $\mathrm{SSH}$ over two cycles of the IOD mode, i.e. the events 1994/1996 and 1997/ 1998. A composite of SSH during the austral spring season (SON) for the two positive IOD phases (IOD+) shows the well-known IOD+ pattern displaying a shallower thermocline in the eastern IO from $10^{\circ} \mathrm{S}$ to $10^{\circ} \mathrm{N}$ and a deeper thermocline west of $80^{\circ} \mathrm{E}$ between $0^{\circ}-15^{\circ} \mathrm{S}$ (Figure 6a) [Webster et al., 1999; Feng and Meyers, 2003]. Contrary to the IOD + , the negative IOD phase (IOD-) has not been described in too much detail. A composite of the IOD(Figure 6b) shows that SSH anomalies extend over a smaller area of the central-western IO than during the IOD+; in particular SSH do not reach the region north of Madagascar. This is probably related to the extension of the wind-forcing itself, and to the proximity or strength of a previous IOD+. The amplitude of the SSH front off Sumatra is $5 \mathrm{~cm}$ lower than that of the IOD+. A cause for this could be a weaker feedback mechanism that strengthens the original SST anomaly. For instance, during the IOD- only an intensification of the equatorial westerlies occurs, while during the IOD + the (a)

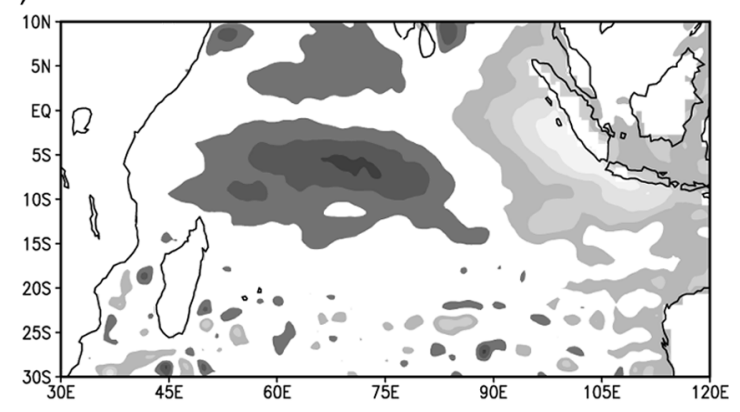

(b)

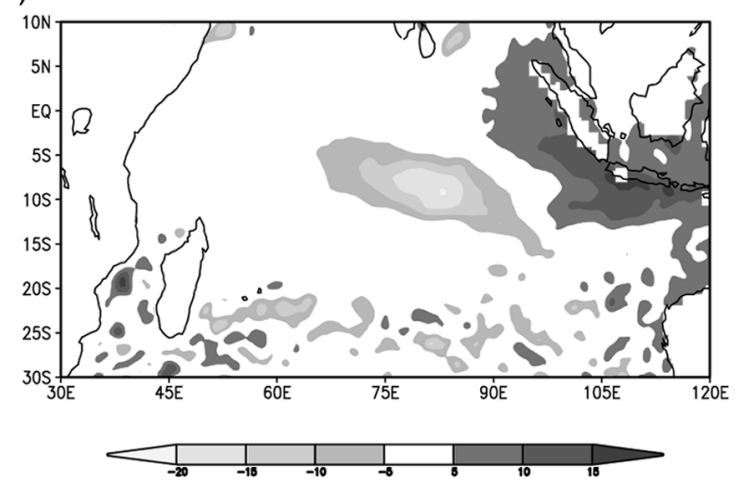

Figure 6. (a) Composite of $\mathrm{SSH}$ anomalies during the austral spring season (SON) for the two strong positive IOD phases of the last decade (1994 and 1997). (b) Same as Figure 6a, but for the two negative IOD phases (1996 and 1998). Units in $\mathrm{cm}$.

winds along the Equator reverse, leading to a strong coupling with the atmosphere [Webster et al., 1999].

[20] A lagged correlation analysis between the time series of the IOD index (Figure 3a) and the basin SSH with a sixmonthly increasing lag between both variables is presented in Figure 7. To focus on interannual timescales, SSH anomalies were low-pass filtered (section 2). (Correlations lower than 0.4 are at the $90 \%$ confidence level not significant, based on a t-student distribution of the correlation coefficient for a basin average, with the degrees of freedom of the $\mathrm{SSH}$ estimated from the autocorrelation function of the low-passed anomalies.)

[21] For lags 1 to 13 months the correlations found are consistent with the description of Feng and Meyers [2003]. After the IOD+ (1 month time lag) negative correlations propagate south along the Indonesian coast and enter the basin between $5^{\circ} \mathrm{S}-20^{\circ} \mathrm{S}$. Afterward ( 7 months time lag) they split into a tropical and subtropical band, while positive correlations associated to forced subtropical Rossby waves are found east of Madagascar [Feng and Meyers, 2003]. During the IOD - (13 months time lag), negative correlations in the central subtropical IO are reinforced by wind curl anomalies and grow in extension from $90^{\circ} \mathrm{E}$ to $60^{\circ} \mathrm{E}$, with a strong SE-NW tilt. Positive correlations remain north and east of Madagascar and appear southwest of the island from the southern tip toward the African coast along the "dipole corridor" [de Ruijter et al., 2004]. Negative correlations 

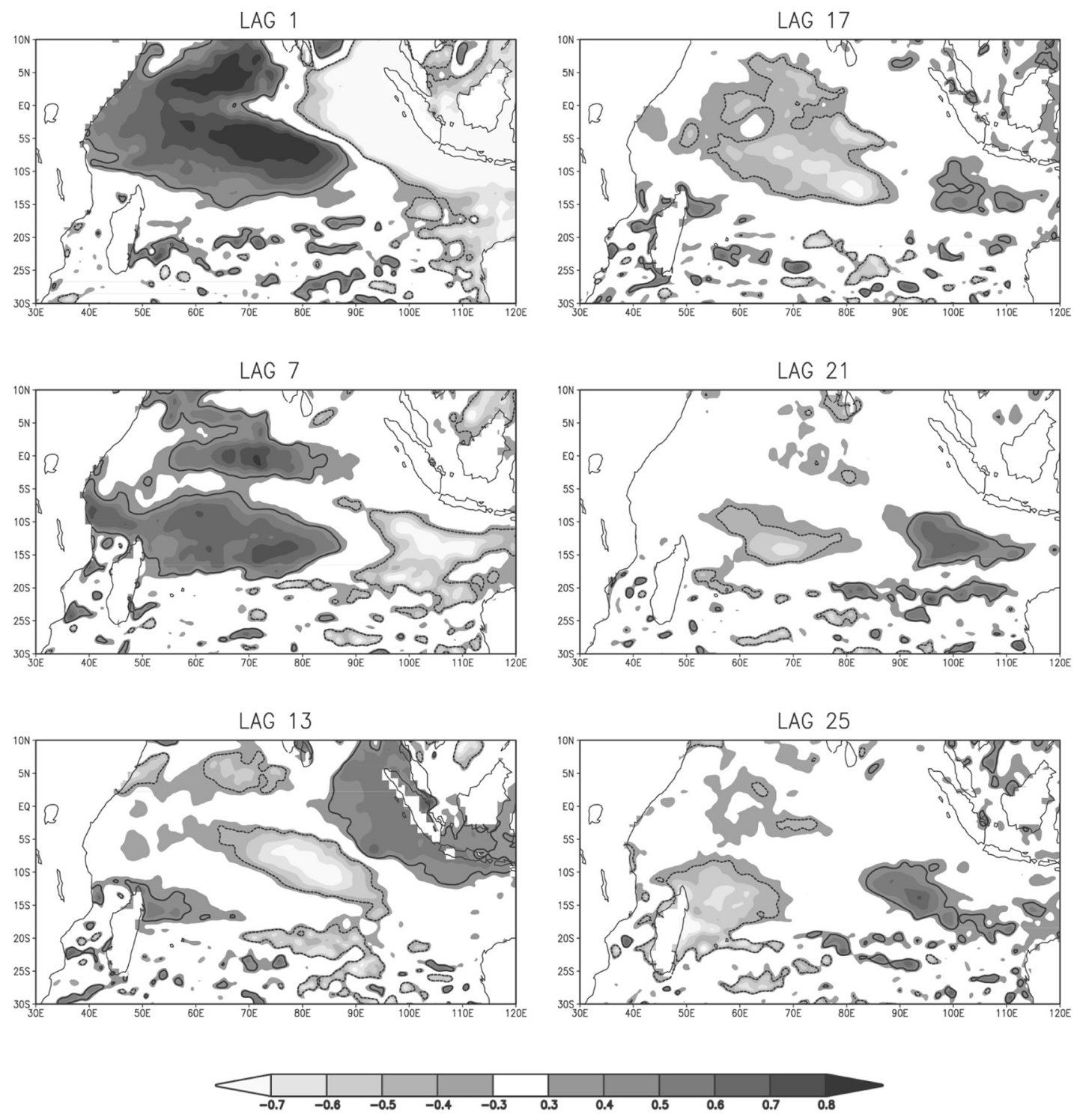

Figure 7. Correlation patterns between the IOD index [Saji et al., 1999] and the basin low-pass filtered SSH. For every spatial point of the IO the correlation coefficient of the IOD index time series with the SSH time series is calculated at the lags shown, with the SSH lagging the index and lags in months. The 0.4 contours are shown to denote areas of significant correlation at the $90 \%$ confidence level based on a t-student distribution for the correlation coefficient. Correlations lower than 0.3 are not shown. Contours every 0.1 units.

between $5^{\circ}$ and $15^{\circ} \mathrm{S}$ propagate like forced upwelling Rossby waves (17 months time lag) and those north of $10^{\circ} \mathrm{S}$ reflect at the western coast [Feng and Meyers, 2003]. Interaction with the wind curl strengthens and extends the core of the subtropical negative correlations to the south (21 months time lag).At the longitude of the Mascarene's Arc the correlations split into northward and southward branches, likely due to interaction with the bottom topography. Afterward, they extend southwestward along the east coast of Madagascar, until they form a large-scale pattern in the Mascarene Basin (25 months time lag). The shape of this pattern seems to result from the subsequent splitting of signals near $60^{\circ} \mathrm{E}$ and at the islands east coast, as well as from interaction with the signals propagating along $20^{\circ} \mathrm{S}$. Correlations extend further along the eastern side of the MZC and around the southern tip of Madagascar. Compared to the 13 months time lag, the negative correlation pattern covers broader areas of the subtropical gyre and extends further into the MZC.

[22] To illustrate the effect of the wind-forcing on the $\mathrm{SSH}$ evolution, the 2 years correlation cycle (Figure 7) is compared with a time-longitude diagram of $\mathrm{SSH}$ along $14^{\circ}-15^{\circ} \mathrm{S}$ and of wind stress curl anomalies averaged in the band $10^{\circ} \mathrm{S}-15^{\circ} \mathrm{S}$ (Figures 8 and 9). Associated to the 1997 IOD+ positive SSH propagate from the central to the western IO in late 1997-1998 (Figure 8), while a large-scale 


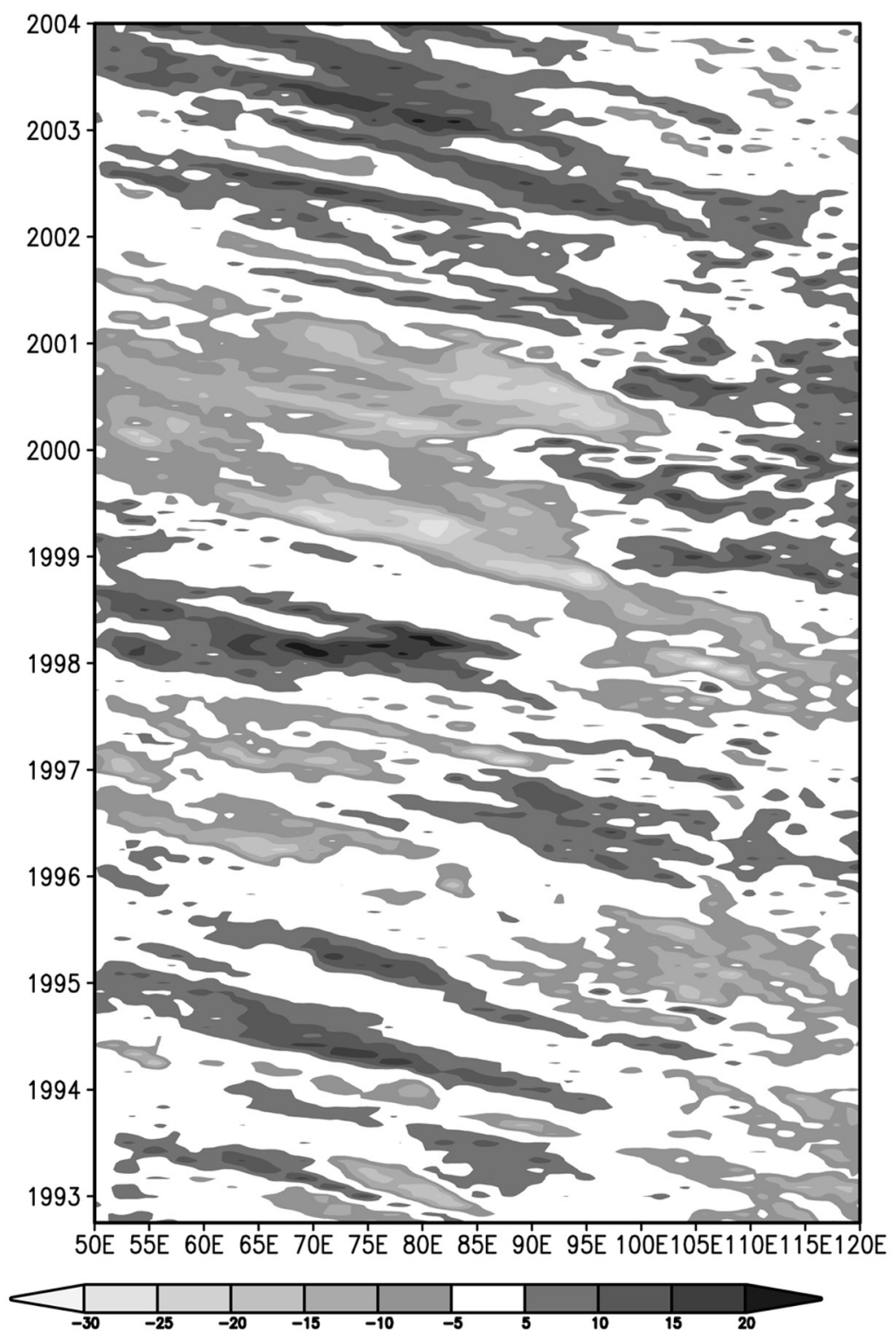

Figure 8. Time-longitude diagram of the $\mathrm{SSH}$ anomalies averaged along the band $14^{\circ}-15^{\circ} \mathrm{S}$. Values lower than $5 \mathrm{~cm}$ are not shown. Units in $\mathrm{cm}$.

positive wind curl anomaly extends across the IO (Figure 9). The negative SSH that enter the basin in early 1998 are reinforced around $95^{\circ} \mathrm{E}$ by negative wind curl anomalies associated to the 1998 IOD-. In early 1999 further wind curl anomalies strengthen the propagating $\mathrm{SSH}$ near $80^{\circ}-85^{\circ} \mathrm{E}$ (Figures 8 and 9). In early 2000, the negative SSH arrive at the coast of Madagascar. The negative wind curl observed between $50^{\circ}$ and $60^{\circ} \mathrm{E}$ probably reinforces the remotely generated $\mathrm{SSH}$ and stimulates a large-scale negative $\mathrm{SSH}$ pattern to be formed around the island. After the 1994 IOD+, negative SSH can be traced only until $95^{\circ} \mathrm{E}$ (Figure 8). The positive wind curl anomaly present in 1995 around $90^{\circ}-95^{\circ} \mathrm{E}$ has acted to weaken or destroy these anomalies (Figure 9). Throughout 1996 negative curl anomalies between $60^{\circ}-95^{\circ} \mathrm{E}$ regenerates negative $\mathrm{SSH}$ that propagate west and form in early 1997 a negative SSH pattern east of Madagascar. Negative SSH from the 1996 IOD- are prob- ably arrested near $60^{\circ} \mathrm{E}$ by the accumulated effect of the positive wind curl anomalies related to the onset of the strong 1997 IOD+.

[23] The wind curl variability in the subtropical IO is related to both the IOD and ENSO cycles [Reason et al., 2000]. For instance, the wind curl anomalies averaged over the region $10^{\circ} \mathrm{S}-15^{\circ} \mathrm{S}, 70^{\circ} \mathrm{E}-100^{\circ} \mathrm{E}$ exhibit a significant correlation with the SOI. This correlation is highest when the wind curl lags the SOI by 3 months $(-0.6)$. Therefore, the $\mathrm{SSH}$ evolution described above may in part be a response to ENSO. In particular, the extremely negative wind curl anomalies observed during 1998-2001 (Figure 9) may reflect signals from the "protracted" La Niña event [Allan et al., 2003]. Overall, the propagation characteristics of the SSH from the 1997/1998 event are consistent with the 2 years timescale found in the correlation analysis (Figure 7). The SSH evolution after the 1994 IOD+ shows a gap in the 


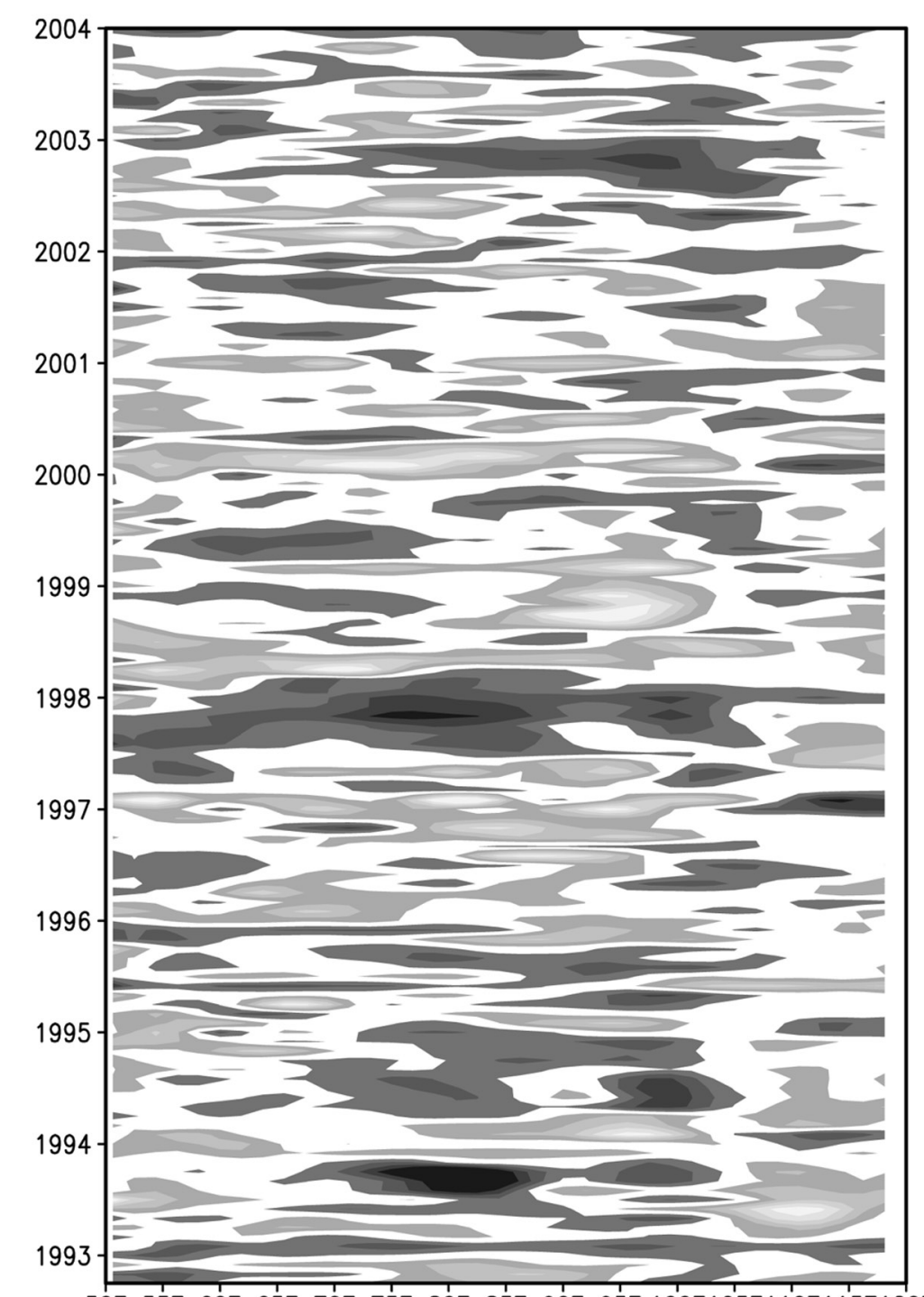

50E 55E 60E 65E 70E 75E 80E 85E 90E 95E 100E105E110E115E120E

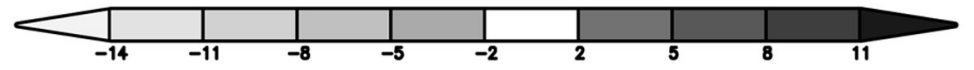

Figure 9. Time-longitude diagram of the wind stress curl anomalies averaged in the band $10^{\circ}-15^{\circ} \mathrm{S}$. Units in $10^{-8} \mathrm{~N} / \mathrm{m}$.

propagating $\mathrm{SSH}$ signals between $85^{\circ} \mathrm{E}-95^{\circ} \mathrm{E}$, related to the absence of IOD- in 1995. Still Figure 8 suggests that SSH in the eastern and western IO may be connected.

\section{Linking the Large-Scale IO Variability and the Mesoscale Activity Around Madagascar}

[24] In this section we examine how the mesoscale activity in the southwest IO (section 3) may be connected to the basin scale variability. The correlation patterns found east of Madagascar the year after the occurrence of a positive and a negative IOD event (Figure 7) suggest that local current regimes are altered by these large-scale SSH anomalies, and subsequently modify the formation of eddies in the area. In other words, changes in the intensity and/or position of tropical and subtropical gyres in the South IO (Figure 1) could occur according to the IOD phases, which in turn modify the flow through the MZC and east and south of Madagascar.

\subsection{Variability of the Local Flow Fields}

[25] To analyze the variability of the SEC regime and its branches at the Madagascar and African coasts, SSH data along the tracks of the T/P and ERS satellites were used to derive geostrophic velocity anomalies. In total, six tracks are selected (see Figure 1). One track east of Madagascar intercepts the SEC at the core of its northern $\left(11^{\circ}-13^{\circ} \mathrm{S}\right)$ and southern $\left(17^{\circ}-20^{\circ} \mathrm{S}\right)$ branches. Tracks selected at the northern tip of Madagascar and at the east Madagascar coast capture the westward flow of the NMC and the southward flowing EMC, respectively. The latter two sections extend 
(a)

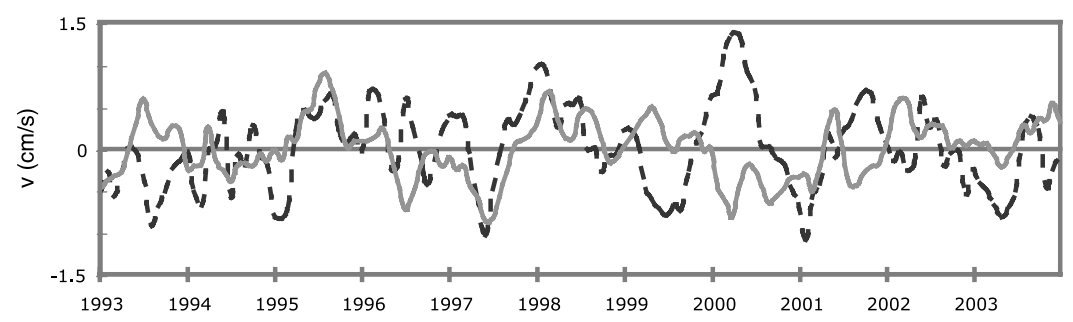

(b)

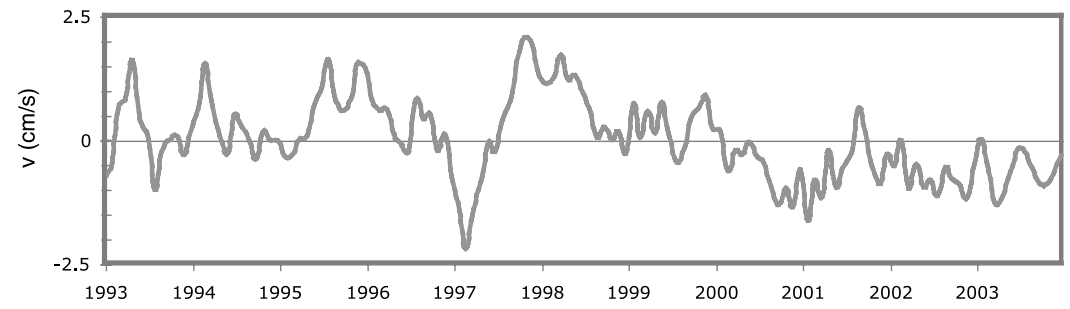

(c)

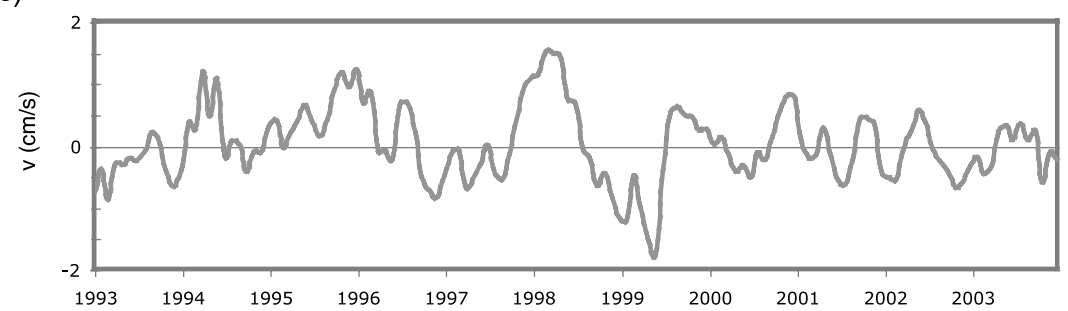

(d)

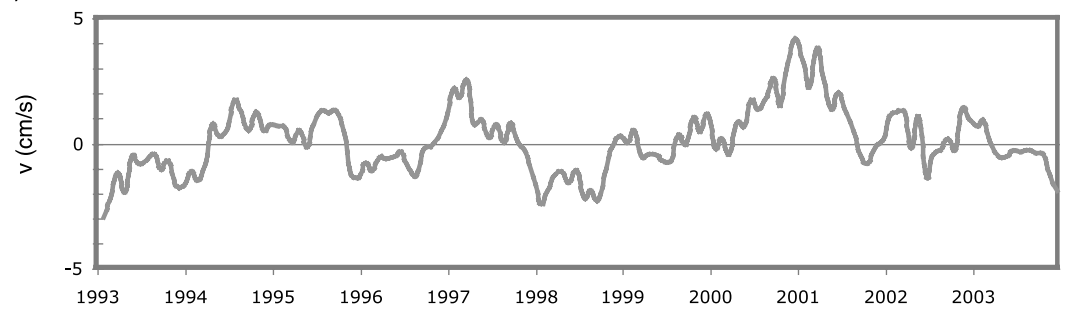

Figure 10. Time series of geostrophic velocity anomalies computed across the combined TP-ERS tracks that intercept the flow of the (a) SEC northern branch (dashed line) and SEC southern branch (solid line), (b) North Madagascar Current (NMC), (c) East Madagascar Current (EMC), and (d) the flow southwest of the narrows in the Mozambique Channel near $18^{\circ} \mathrm{S}$. Positive anomalies mean less intense flow. All the series were smoothed with a three months running mean filter, except in Figure 10d, in which a five months running mean was applied.

$100 \mathrm{~km}$ and $60 \mathrm{~km}$ from the nearest point to the coast, which is consistent with the observations of Swallow et al. [1988] for the width of the NMC and EMC. Two other tracks intercept the flow close to the African coast through the MZC narrows at $17^{\circ} \mathrm{S}$ and the flow of the EACC at $5^{\circ} \mathrm{S}$. Finally, a track at the southern tip of Madagascar captures the EMC westward flow and its possible retroflection path (EMCR). To filter out mesoscale signals in the velocity anomalies, the time series are smoothed using a three months running mean filter.

[26] Figure 10a illustrates that during and after an IOD+ (i.e. in 1995 and in late-1997/1998) there is a decrease in the flow of both SEC branches as well as in the NMC, EMC (Figures $10 \mathrm{~b}$ and 10c) and EACC (not shown). These anomalies suggest that positive SSH from an IOD+ situated in the tropical and subtropical IO (Figure 7, lags = 1 to 13 months) tend to reduce the intensity of the tropical gyre, and/or induce a northward extension of the subtropical gyre. The response to the IOD - in 1999 is an intensification of the SEC northern branch (Figure 10a), the EMC (Figure 10c) and also of the EACC. In early 1997 and 2000 there is an increase in both the SEC southern branch and the NMC (Figures 10a and 10b). These anomalies point to a strengthening and/or southward extension of the tropical gyre related to negative $\mathrm{SSH}$ of the IOD- (Figure 7, lags $=13$ to 25 months). The velocity anomalies through the narrows of the MZC (Figure 10d) show an interannual oscillation, with increased flow in 1998 and decreased flow in 1997 and 2000-2001, i.e. after the respective IOD+ and IOD- events. The increase in the NMC observed during 2002-2003 (Figure 10b) might be due to the persistence of a stronger tropical gyre.

[27] To evaluate variations in the intensity and/or position of the tropical and subtropical gyres in the IO, SSH anomalies 
(a)

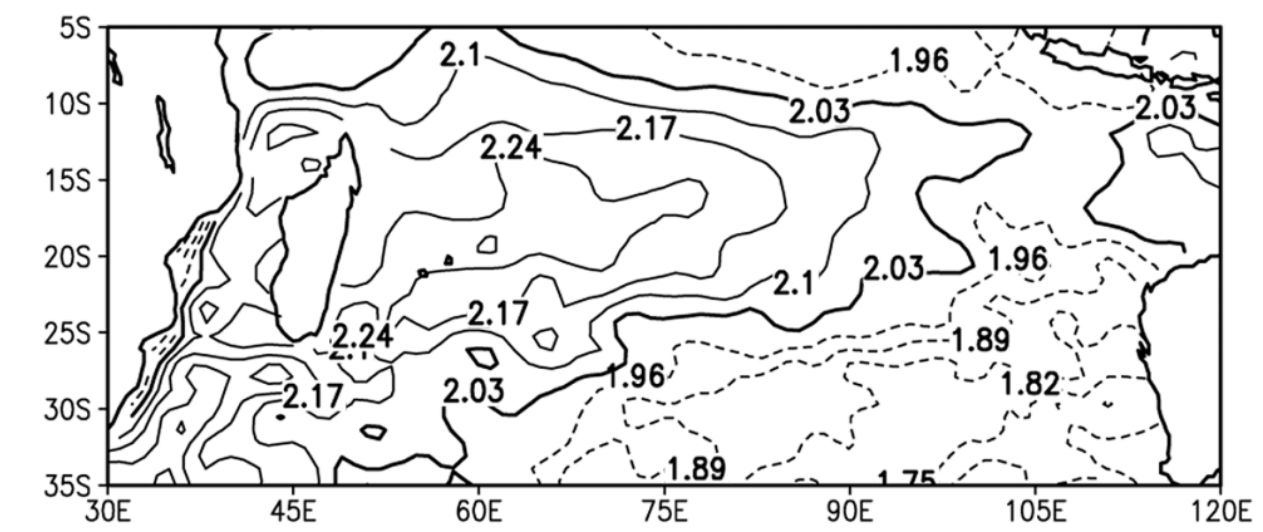

(b)

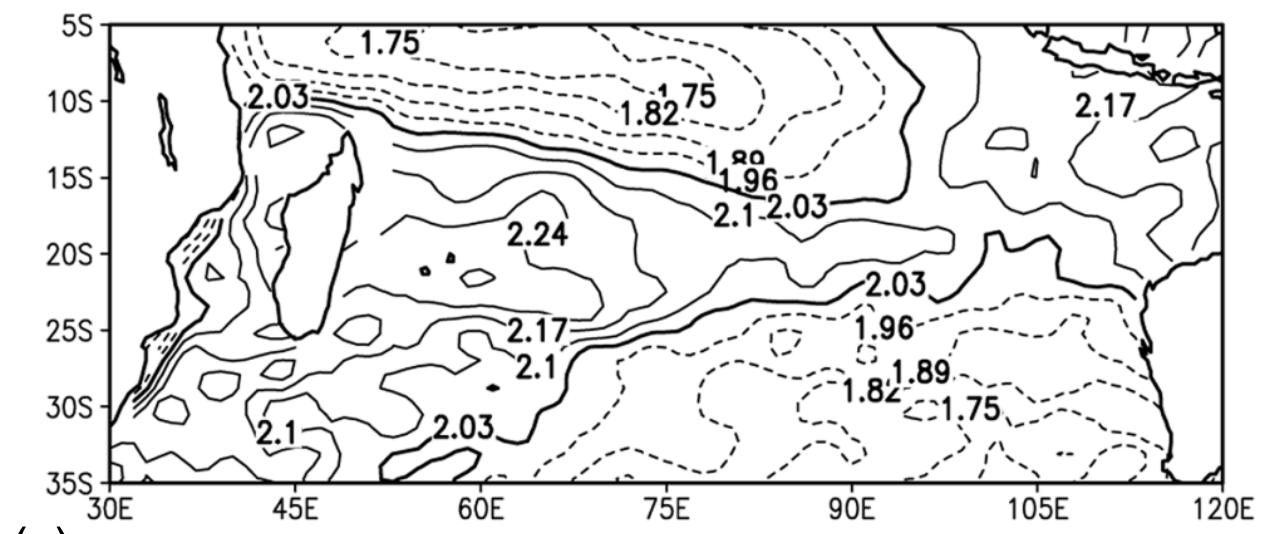

(c)

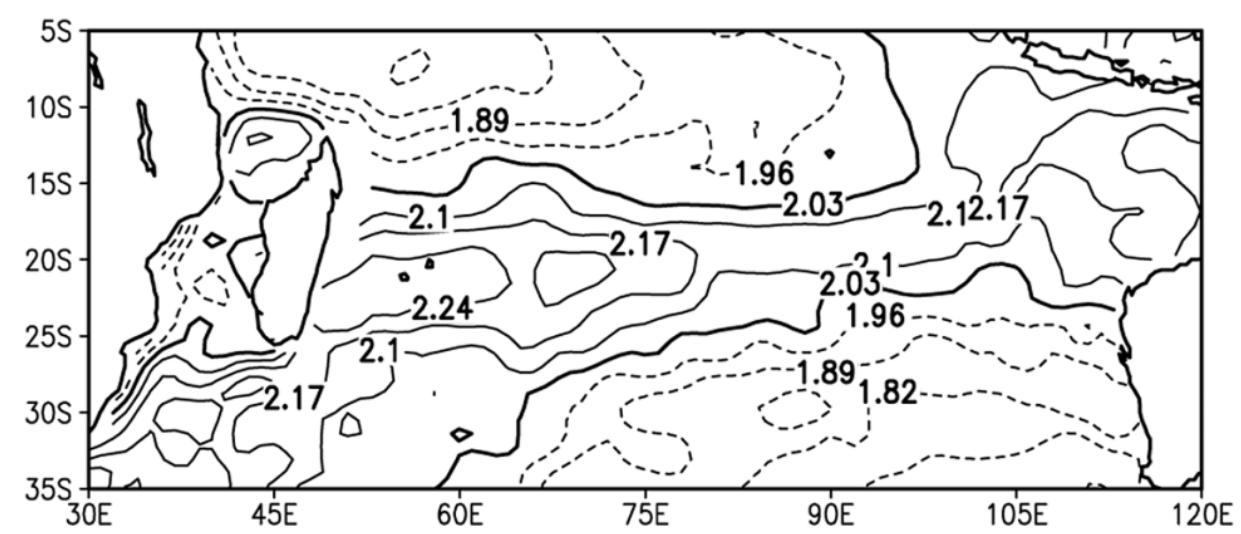

Figure 11. Total SSH field in the South IO averaged (a) from December 1997 to May 1998, (b) from December 1998 to May 1999, and (c) in 2000. SSH anomalies from altimetry were superimposed to a mean dynamic topography in the IO [Rio and Hernandez, 2004] to derive the time-varying sea level. The 2.03 contour is thicker and denotes the limit between the tropical and subtropical gyres. After the 1997 IOD+ the subtropical gyre extends northward up to $5^{\circ} \mathrm{S}$ (Figure 11a). In contrast, after the 1998 IOD-, the tropical gyre intensifies and extends down to $15^{\circ} \mathrm{S}$ in the central Indian Ocean (Figure 11b). Eventually in 2000 the southern boundary of the tropical gyre is around $15^{\circ} \mathrm{S}$ (Figure $11 \mathrm{c}$ ). Units in $\mathrm{cm}$.

from altimetry are combined with the mean dynamic topography CMDT-RIO03 [Rio and Hernandez, 2004] available on a $1^{\circ} \times 1^{\circ}$ grid. The variability of the total sea level from 1998 to 2000 is shown as composites of the total SSH fields over the two seasons following the 1997 IOD+ and the 1998 IOD- (i.e. DJF and MAM), and over 2000 (Figure 11). The boundary between the tropical and subtropical gyres in the IO is found around $12^{\circ} \mathrm{S}$ (marked by the 2.03 contour). In the first half of 1998 (Figure 11a), the subtropical gyre extends up to $5^{\circ} \mathrm{S}$, so it penetrates into the region of the tropical gyre. This situation reverses in 1999 when the tropical gyre is intensified and extends down to $15^{\circ} \mathrm{S}$ in the central IO $\left(90^{\circ} \mathrm{E}\right)$, and eventually in 2000 , its southern limit is found along $15^{\circ} \mathrm{S}$ across the basin. The tropical gyre has recovered its normal 
(a)

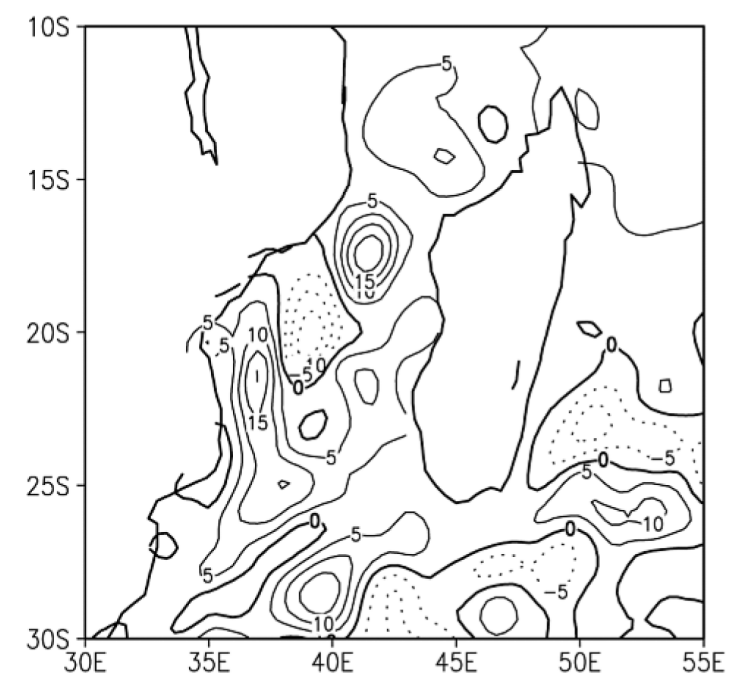

(b)

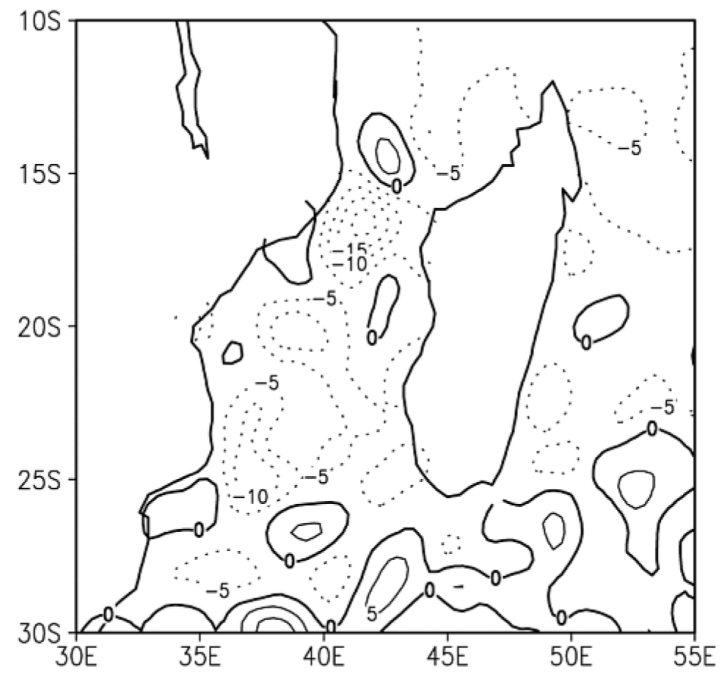

Figure 12. Composite of the SSH anomaly fields around Madagascar during (a) high EKE events and (b) low EKE events. For the high EKE composite six SSH fields that correspond to the EKE peaks that appear in the central Mozambique Channel (CC in Figure 2) in Dec 95, Jan 98, Sep 98, Dec 98, Mar 99 and May 99 are averaged. For the low EKE composite seven SSH fields that correspond to the weak EKE peaks observed in Mar 97, Jun 97, Feb 00, Jun 00, Sep 00, Dec 00 and Mar 01 are considered. Units in cm.

position during 2001-2002 (not shown). Although the response to the 1994/1996 IOD cycle is weaker, it shows a similar weakening and southward extension of the tropical gyre in DJF 1995 and DJF 1997, respectively. Application of the island rule [Godfrey, 1989] indicates that a extension of the subtropical gyre east of the island and/or a reduced tropical gyre, would induce a larger southward flow through the Channel, and vice versa. Liu et al. [1999] show a similar response of the island circulation to remotely forced long Rossby waves. In this sense, the variability of the flow through the MZC from 1997 to 2001 (Figure 10d) is in agreement with the large scale SSH anomalies arriving to the east of Madagascar during those years (Figure 8).

\subsection{Impact on the Mozambique Channel Eddy Activity}

[28] Two periods of high EKE (1996, early 1998 and 1999) and low EKE (1997, 2000-2001) are observed in the CC region (Figure 5a), which coincide with years over which the flow in the narrows was relatively high and low, respectively (Figure 10d). The EKE in CC shows a significant correlation with the local SSH field (section 3), and with that north of the Channel. In turn, the latter is highly correlated with the SSH field east of Madagascar that represents Rossby wave signals arriving from the central IO.

[29] To analyze the relation between the flow through the narrows and eddies further south, SSH composites are produced. For the high EKE composite, six out of eight EKE peaks associated to anticyclonic anomalies during 1996-2001 are averaged, specifically the SSH fields that correspond to the EKE peaks that appear in CC two months later (Figure 5). Similarly, for the low EKE period, we select the SSH fields associated to small EKE peaks in CC. Seven out of nine of these low EKE events are included in the composite. All the selected events have similar characteristics with respect to the origin and propagation of the positive SSH anomalies traced through Channel, which are well represented in the composites (Figure 12).

[30] Over the period of high EKE, Figure 12a shows an anticyclonic anomaly $(20 \mathrm{~cm})$ in the narrows, while east and north of Madagascar large scale positive SSH are seen. It is suggested that a stronger southward jet in the western part of the narrows induces or reinforces eddies coming from the north. At the same time an anticyclonic anomaly appears in the MZC between $20^{\circ}-24^{\circ} \mathrm{S}$. Schouten et al. [2003] proposed that eddies in the central part of the Channel can grow due to merging with other elongated positive $\mathrm{SSH}$ anomalies that propagate from its eastern part. Altimetry data indicates that all the anticyclonic anomalies detected over the period 1996 and 1998-1999 experienced merging at some stage of their propagation. In particular, an elongated anomaly was observed to move off the western Madagascar coast in Jan 99 and to interact with an eddy south of the narrows in Mar 99. The two EKE events left out from the composite did not show a clear relation with the flow in the narrows.

[31] The low EKE period (Figure 12b) shows a cyclonic anomaly $(-20 \mathrm{~cm})$ in the narrows and negative SSH in the north and northeast Madagascar regions, while in the central Channel no anticyclones are observed. This picture suggests that weaker currents in the narrows and the absence of positive SSH inhibit the growth of eddies. The weak positive SSH seen around $14^{\circ} \mathrm{S}$ could represent an eddy formed north of the narrows. Examples of these are observed in Feb 00, Sep 00 and Jan 01 . They probably correspond to the eddies measured by Ridderinkhof and de Ruijter [2003] in Apr 00, Sep 00 and Feb 01, respectively. They were considerably reduced after passing the narrows, where a destructive merging between both SSH anomalies seems to occur. In particular, the anticyclones observed in Apr 00 and Sep 00 became weaker and got 'squeezed' toward the African coast after a large elongated negative SSH appeared in Jul 00 and Dec 00 . Thus, the $4-5$ times/year frequency observed in 


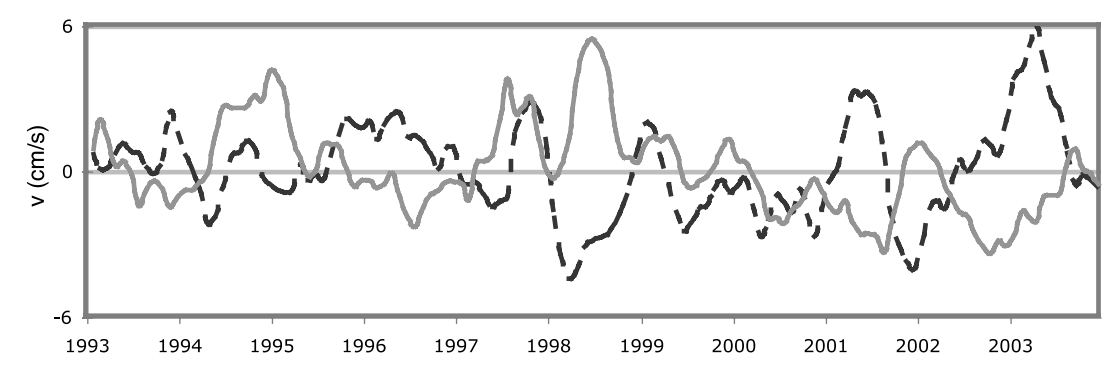

Figure 13. Same as Figure 10, but for the flow at the southern tip of Madagascar along the EMC westward path (gray line) and the flow along the possible EMC retroflection path (EMCR) (dashed line). In the former negative anomalies mean more intense westward flow; in the latter negative anomalies mean less intense eastward flow. Both time series were smoothed with a five months running mean filter.

the transport through the narrows [Ridderinkhof and de Ruijter, 2003] seems to reduce further south due to the interaction with the negative SSH field from the eastern Channel.

\subsection{Connection to the Eddy Activity South of Madagascar}

[32] In the SM region no unique relationship between the EKE and the EMC variability could be established from the data. The EKE minimum observed from 1998 to 1999 (Figure $5 \mathrm{~b}$ ) could be a lagged response to the weakening of the EMC in 1998 (Figure 10c). For instance, from 1998 to half 1999 positive SSH dominate the area around the southern tip of Madagascar (see Figure 3c), suggesting a decrease in the cyclonic activity from the EMC. On the other hand, the EKE peaks during 1996-1997 and 2000-onwards lack periods of relatively more intense EMC. This seems to reflect that the EKE in this region is not only influenced by tropical variability through the EMC regime, but also by variability coming from the subtropical band $20-30^{\circ} \mathrm{S}$ and mid latitudes. In particular, the negative SSH observed in EM (Figure $3 \mathrm{~b}$ ) during the two periods of regular dipole formation [de Ruijter et al., 2004] are related to negative signals from the IOD + propagating along $\sim 20^{\circ} \mathrm{S}$ (Figure 7).

[33] It is also expected that anomalies in the flow south of Madagascar appear due to the negative SSH associated to a stronger tropical gyre in 1999-2000. Velocity anomalies across the EMC and EMCR display an anti-phase relation over most of the years; however, this is not seen in 19992000 (Figure 13). Instead, in 2000 a stronger westward jet south of Madagascar is seen. The extra transport toward the African coast could have been carried by the dipoles that later join the Agulhas retroflection regime [de Ruijter et al., 2004]. Different than other years, this train of dipoles propagated almost straight toward the AC.

\section{Summary and Discussion}

[34] We have used sea level data from T/P and ERS satellites for the period 1992-2003 to study the interannual variability of the SSH and EKE fields in the Mozambique Channel (MZC) and south of Madagascar. In particular, the goal of this study was to investigate a possible link between the mesoscale eddy field in these two regions and the largescale Indian Ocean (IO) variability via changes in the western IO upper layer currents. Large-scale SSH signals related to the occurrence of the IOD cycle in the Tropical IO propagate in the subtropical IO as forced Rossby waves that arrive at the coast of Madagascar about 1 year after each IOD phase (see Figure 7). By computing geostrophic velocity anomalies from altimetry, we found that sea level anomalies due to a positive IOD event induce a weakening in the surface flow of the South Equatorial Current (SEC) west of the Mascarene's Arc and its branches at the Madagascar and African coasts. Opposite, the response to a negative IOD event is an intensification of these currents. As a consequence, an intensification and northward (southward) extension of the subtropical (tropical) gyre is seen after the positive (negative) IOD phase (see Figure 11). In response, the mesoscale eddy activity in the central MZC shows periods of high (low) EKE after a positive (negative) IOD event (see Figure 5).

[35] The SSH field in the northern and central MZC shows a significant interannual oscillation related to the IOD phases. Especially after the 1997/1998 IOD a 2 years period of positive $\mathrm{SSH}$ anomalies was followed by a 2 years period of negative SSH anomalies. Variations in the EKE in the central Channel (CC) are dominated by a similar interannual modulation, which is not apparent in the EKE to its north. The difference is explained in part by variations in the currents through the narrows of the Channel. After the positive IOD phase, the relatively stronger currents seem to reinforce eddies coming from the north. Additionally, the dominant positive SSH stimulate merging and further growth of the anticylonic anomalies in the central Channel. Therefore, periods of high EKE coincide with high amplitude eddies that are ultimately responsible for a larger southward transport through the MZC. In contrast, after the negative IOD phase a cyclonic anomaly in the flow through the narrows seems to weaken eddies passing by, while the predominance of negative SSH inhibit merging (i.e. very weak or no anticyclones are present). A decrease in the southward transport results.

[36] The formation of eddies north of the MZC is characterized by a 7 times/year frequency induced by barotropic instability of the SEC [Quadfasel and Swallow, 1986]. Farther south, this frequency is reduced to $4-5$ times/year [Schouten et al., 2003]. Schouten et al. [2002b] proposed variations in the process of eddy formation via a highfrequency teleconnection with the IO equatorial winds. This study shows that the dominant effect of the equatorialtropical signals from the IOD on the mesoscale variability in the MZC is by variations in the flows around Madagascar due to the arrival of large-scale SSH anomalies. For instance, the period of reduced eddy formation in the first half of 1998 [Schouten et al., 2003] coincides with the northward shift of 
the subtropical gyre that probably caused a reduction of the instability of the SEC-jet north of Madagascar.

[37] The SSH variability in the region east of Madagascar (EM) shows an interannual signal similar to the one in CC. This SSH signal could lead to some of the interannual changes observed in the EKE further south. For example, during the 4 years oscillation from 1998 to 2001, positive (negative) SSH anomalies east of Madagascar seem to be unfavorable (favorable) for the formation of dipoles southeast of the island. However, we did not find a single relation between the anomalies in the EMC and the EKE southwest of Madagascar (SM). Probably, variability coming from the subtropical and midlatitude IO are also key factors for the eddy activity in this region.

[38] Finally, the variability of the large-scale SSH during the last decade has been influenced by the occurrence of ENSO events that coincided with the IOD phases. The Indonesian Throughflow (ITF) entering the basin between $10^{\circ}$ and $15^{\circ} \mathrm{S}$ is another cause of interannual variability in the IO not independent of ENSO [Meyers, 1996]. Ultimately, it is the wind curl in the central IO that eventually modulates the SSH variability arriving east of Madagascar [Masumoto and Meyers, 1998]. In addition, wind curl anomalies in the western IO seem essential for the development of the large negative SSH patterns occurring east of Madagascar. Which factors control the variability of the local wind field, including links to IOD, ENSO or interannual variations of the monsoon system, needs further investigation.

[39] Understanding the year-to-year variations in the flows around Madagascar is relevant for both the local and global circulation dynamics and variability. Schouten et al. [2002a] showed that eddies from the MZC and south Madagascar are a control on the shedding of Agulhas Rings south of Africa, and therefore impact on the Indian-Atlantic interocean exchange. We found that large-scale SSH anomalies related to the IOD mode induce changes in the surface currents in the western IO that subsequently alter the EKE in the central Channel and eventually the southward throughflow. Although a lag of about 1.5 year is detected between an IOD peak and the EKE interannual variability in the central Channel, the analysis is limited by the length of the available time series and the conclusions depend on only a few IOD events. It is therefore necessary to continue monitoring the SSH interannual variations in the subtropical IO and around Madagascar.

[40] Acknowledgments. We thank Mathijs Schouten for stimulating discussions and help with the management of altimetry data. This research was funded by the Foundation for Earth and Live Sciences (ALW) of the Netherlands Foundation of Scientific Research (NOW) under grant 854.00 .001 .

\section{References}

Allan, R. J., C. J. C. Reason, J. A. Lindesay, and T. J. Ansell (2003), Protracted ENSO episodes and their impacts in the Indian Ocean region, Deep Sea. Res., 50, 2331-2347.

Biastoch, A., and W. Krauss (1999), The role of the mesoscale eddies in the source regions of the Agulhas Current, J. Phys. Oceanogr., 29, $2303-$ 2317.

de Ruijter, W. P. M., H. Ridderinkhof, J. R. E. Lutjeharms, M. W. Schouten, and C. Veth (2002), Observations of the flow in the Mozambique Channel, Geophys. Res. Lett., 29(10), 1502, doi:10.1029/2001GL013714.

de Ruijter, W. P. M., H. M. van Aken, E. J. Beier, J. R. E. Lutjeharms, R. P. Matano, and M. W. Schouten (2004), Eddies and dipoles around South Madagascar: Formation, pathways and large-scale impact, Deep Sea Res., Part I, 51, 383-400.

Donguy, J. R., and B. Piton (1991), The Mozambique Channel revisited, Oceanol. Acta, 14, 549-558.
Duchon, C. E. (1979), Lanczos filtering in one and two dimensions, J. Appl. Meteorol., 18, 1016-1022.

Fang, F., and R. Morrow (2003), Evolution, movement and decay of warmcore Leeuwin Current eddies, Deep Sea Res., 50, 2245-2261.

Feng, M., and G. Meyers (2003), Interannual variability in the tropical Indian Ocean: A two year time-scale of the Indian Ocean dipole, Deep Sea Res., Part II, 50, 2263-2284.

Godfrey, J. S. (1989), A Sverdrup model of the depth-integrated flow for the world ocean allowing for island circulations, Geophys. Astrophys. Fluid Dyn., 45, 89-112.

Gründlingh, M. L. (1995), Tracking eddies in the southeast Atlantic and southwest Indian oceans with TOPEX/OSEIDON, J. Geophys. Res., 100, 24,977-24,986.

Kalnay, E., et al. (1996), The NCEP/NCAR 40 Year Reanalysis Project, Bull. Am. Meteorol. Soc., 77, 437-471.

Liu, Z., L. Wu, and H. Hurlburt (1999), Rossby wave-Coastal Kelvin wave interaction in the extratropics. Part II: Formation of island circulation, J. Phys. Oceanogr., 29, 2418-2505.

Lutjeharms, J. R. E. (1988), Remote sensing corroboration of the retroflection of the East Madagascar current, Deep Sea Res., 35, 2045-2050

Masumoto, Y., and G. Meyers (1998), Forced Rossby waves in the southern tropical Indian Ocean, J. Geophys. Res., 103, 27,589-27,602.

Meyers, G. (1996), Variation of Indonesian throughflow and the El Nino Southern Oscillation, J. Geophys. Res., 101(C5), 12,255-12,263.

Murtugudde, R., A. J. Busalacchi, and J. Beauchamp (1998), Seasonal to interannual effects of the Inodensian Trhoughflow on the tropical IndoPacific basin, J. Geophys. Res., 103, 21,425-21,441.

Nicholson, S. E. (1997), An analysis of the ENSO signal in the tropical Atlantic and western Indian oceans, Int. J. Climatol., 17, 345-375.

Palastanga, V., et al. (2006), Flow structure and variability in the subtropical Indian Ocean, J. Geophys. Res., doi:10.1029/2005JC003395, in press.

Perigaud, C., and P. Delecluse (1993), Interannual sea level variations in the Tropical South Indian Ocean from Geosat and shallow water simulations, J. Phys. Oceanogr., 23, 1916-1934.

Quadfasel, D. R., and J. C. Swallow (1986), Evidence for 50-day period planetary waves in the South Equatorial Current of the Indian Ocean, Deep Sea Res., 33, 1307-1312.

Quartly, G. D., and M. A. Srokosz (2004), Eddies in the Southern Mozambique Channel, Deep. Sea Res., Part II, 51, 69-83.

Rao, S. A., S. K. Behera, Y. Masumoto, and T. Yamagata (2002), Interannual subsurface variability in the tropical Indian Ocean with a special emphasis on the Indian Ocean dipole, Deep Sea Res., Part II, 49, 1549-1572.

Reason, C. J. C., R. J. Allan, J. A. Lindesay, and T. J. Ansell (2000), ENSO and climatic signals across the Indian Ocean basin in the global context: Part I, Interannual composite patterns, Int. J. Climatol., 20, 1285-1327.

Ridderinkhof, H., and W. P. M. de Ruijter (2003), Moored current observations in the Mozambique Channel, Deep Sea Res., Part II, 50, 1933-1955.

Rio, M.-H., and F. Hernandez (2004), A mean dynamic topography computed over the world ocean from altimetry, in situ measurements, and a geoid model, J. Geophys. Res., 109, C12032, doi:10.1029/2003JC002226.

Saji, N. H., B. M. Goswami, and P. N. Vinayachandran (1999), A dipole mode in the tropical Indian Ocean, Nature, 401, 360-363.

Schouten, M. W., W. P. M. de Ruijter, and P. J. van Leeuwen (2002a), Upstream control of Agulhas Ring shedding, J. Geophys. Res., 107(C8), 3109, doi: $10.1029 / 2001 \mathrm{JC} 000804$

Schouten, M. W., W. P. M. de Ruijter, P. J. van Leeuwen, and H. Dijkstra (2002b), A teleconnection between the equatorial and southern Indian Ocean, Geophys. Res. Lett., 29(16), 1812, doi:10.1029/2001GL014542.

Schouten, M. W., W. P. M. de Ruijter, P. J. van Leeuwen, and H. Ridderinkhof (2003), Eddies and variability in the Mozambique Channel, Deep Sea Res., Part II, 50, 1987-2003.

Stramma, L., and J. R. E. Lutjeharms (1997), The flow field of the subtropical gyre of the South Indian Ocean, J. Geophys. Res., 102, 5330-5513.

Swallow, J., M. Fieux, and F. Schott (1988), The boundary currents east and north of Madagascar: 1. Gesotrophic Currents and transports, J. Geophys. Res., 93, 4951-4962.

Webster, P. W., A. M. Moore, J. P. Loschnigg, and R. R. Lebben (1999), Coupled ocean-atmosphere dynamics in the Indian Ocean during 199798, Nature, 401, 356-360.

Wijffels, S., and G. Meyers (2004), An intersection of oceanic wave-guides: Variability in the Indonesian Throughflow region, J. Phys. Oceanogr., 34, $1232-1253$

Xie, S. P., H. Annamalai, F. A. Schott, and J. P. McCreary Jr. (2002), Structure and mechanisms of South Indian Ocean climate variability, J. Clim., 15, 864-878.

W. P. M. de Ruijter, V. Palastanga, and P. J. van Leeuwen, Institute for Marine and Atmospheric Research, Utrecht University, 3508 Utrecht, Netherlands. (v.palastanga@phys.uu.nl) 